\title{
Crystal Structure of the Amyloid- $\beta$ p 3 Fragment Provides a Model for Oligomer Formation in Alzheimer's Disease
}

\author{
Victor A. Streltsov, ${ }^{1}$ Joseph N. Varghese, ${ }^{1}$ Colin L. Masters, ${ }^{2}$ and Stewart D. Nuttall ${ }^{1}$ \\ ${ }^{1}$ Commonwealth Scientific and Industrial Research Organization Materials Science and Engineering, and Preventative Health Flagship, Parkville, Victoria \\ 3052, Australia, and ${ }^{2}$ Mental Health Research Institute, University of Melbourne, Parkville, Victoria 3010, Australia
}

\begin{abstract}
Alzheimer's disease is a progressive neurodegenerative disorder associated with the presence of amyloid- $\beta(\mathrm{A} \beta)$ peptide fibrillar plaques in the brain. However, current evidence suggests that soluble nonfibrillar $\mathrm{A} \beta$ oligomers may be the major drivers of $\mathrm{A} \beta$-mediated synaptic dysfunction. Structural information on these $\mathrm{A} \beta$ species has been very limited because of their noncrystalline and unstable nature. Here, we describe a crystal structure of amylogenic residues 18 - 41 of the A $\beta$ peptide (equivalent to the p $3 \alpha / \gamma$-secretase fragment of amyloid precursor protein) presented within the CDR3 loop region of a shark Ig new antigen receptor (IgNAR) single variable domain antibody. The predominant oligomeric species is a tightly associated $\mathrm{A} \beta$ dimer, with paired dimers forming a tetramer in the crystal caged within four IgNAR domains, preventing uncontrolled amyloid formation. Our structure correlates with independently observed features of small nonfibrillar $\mathrm{A} \beta$ oligomers and reveals conserved elements consistent with residues and motifs predicted as critical in $\mathrm{A} \beta$ folding and oligomerization, thus potentially providing a model system for nonfibrillar oligomer formation in Alzheimer's disease.
\end{abstract}

\section{Introduction}

The major constituent of Alzheimer's disease (AD) plaques is the amyloid- $\beta$ peptide $(\mathrm{A} \beta)$, which is cleaved from the membranebound amyloid precursor protein (APP) via the $\beta / \gamma$-secretase pathway (Querfurth and LaFerla, 2010). However, an emerging consensus is that small soluble $\mathrm{A} \beta$ nonfibrillar oligomers and not the amyloid plaques per se could be the earliest mediators of neuronal dysfunction (Walsh and Selkoe, 2007; Shankar et al., 2008). Critically, obtaining structural information for $A \beta$ peptide and its oligomers/fibrils has been and remains a major challenge (Kajava et al., 2006; Nelson and Eisenberg, 2006). Atomic resolution structures have been reported for microcrystals of short amyloid fragments only (Sawaya et al., 2007). Crystallographic studies of $A \beta$ complexed/fused with other proteins include the following: (1) IDE (insulin-degrading enzyme) in complex with $\mathrm{A} \beta_{40}$ (Shen et al., 2006), in which only $\mathrm{A} \beta$ residues $1-3$ and 16-23 were observed; (2) the immunodominant B-cell epitope of the $\mathrm{A} \beta_{1-8}$ fragment in complex with murine antibodies, which revealed extended coil-like conformations of the epitope (Gardberg et al., 2007; Miles et al., 2008); and (3) the $\mathrm{A} \beta_{28-42}$ fragment fused with the $\mathrm{C}$ terminus of ribonuclease $T k$-RNase HII, which illustrated a limited $\beta$-conformation (Takano et al., 2006).

\section{Received Aug. 14, 2010; revised Nov. 9, 2010; accepted Nov. 18, 2010}

We thank Nicola Bartone and Dr. Lindsay Sparrow (Commonwealth Scientific and Industrial Research Organization Materials Science and Engineering) for N-terminal sequencing and mass spectroscopy, Dr. Janet Newman for her advice in crystallization trials, Dr. Shane Seabrook for performing the dynamic light scattering, and Ryan Naylor, Dr. Remy Robert, Dr. Andy Hill, Dr. Joe Ciccotosto, Varsha Lal, and Sonia Sankovich for biological assays. We gratefully acknowledge the Australian Synchrotron for access to MX1 beamline.

Correspondence should be addressed to either Dr. Victor A. Streltsov or Dr. Stewart D. Nuttall, Commonwealth Scientific and Industrial Research Organization Materials Science and Engineering, 343 Royal Parade, Parkville, VIC 3052, Australia. E-mail: victor.streltsov@csiro.au or stewart.nuttall@csiro.au.

DOI:10.1523/JNEUROSCI.4259-10.2011

Copyright $\odot 2011$ the authors $\quad 0270-6474 / 11 / 311419-08 \$ 15.00 / 0$
Nuclear magnetic resonance (NMR) data interpretations of fibrils formed from different $\mathrm{A} \beta$ peptides infer either parallel or antiparallel orientations of the $\beta$-sheets (Lynn and Meredith, 2000; Egnaczyk et al., 2001; Tycko, 2001). Additional NMR studies (Sorimachi et al., 1990; Petkova et al., 2002, 2006; Lührs et al., 2005; Sato et al., 2006) proposed fibril models for $\mathrm{A} \beta_{1-42}$ as parallel-stacked hairpin-like structures of $\mathrm{A} \beta$ peptides. Residues $1-9 / 17$ are unstructured, whereas residues $18-42$ form a $\beta$-strand-turn- $\beta$-strand hairpin motif that contains two intermolecular, parallel, in-register $\beta$-sheets formed by residues $18-26$ and 31-42. Solid-state NMR study (Chimon and Ishii, 2005; Chimon et al., 2007) of $\mathrm{A} \beta_{1-40}$ fibril intermediates excluded the possibility of a direct conversion of monomeric $\mathrm{A} \beta$ to fibril and suggested formation an earlier intermediate species that does not contain fibril like cross- $\beta$ sheets. Notably, the more recent NMR data (Yu et al., 2009) indicated that specific soluble form of $\mathrm{A} \beta_{1-40}$ nonfibrillar oligomer (globulomer) contained a peptide dimer repeat with mixed intermolecular parallel and intramolecular antiparallel $\beta$-sheet structure for residues $18-40$. The first 16 residues are disordered in this oligomer structure.

There is strong evidence that $\mathrm{A} \beta$ spontaneously aggregates into $\beta$-sheet-rich oligomers/fibrils resembling those in the $\mathrm{AD}$ brain plaques. For example, studies using atomic force microscopy and scanning tunneling microscopy showed that the structures of dimers, tetramers, and other low-molecular-weight (MW) $\mathrm{A} \beta$ oligomers were consistent with the model of the $\mathrm{A} \beta$ monomers as $\beta$-hairpins (Losic et al., 2006; Mastrangelo et al., 2006). The most recent and accurate circular dichroism (CD) measurements of $\mathrm{A} \beta_{1-40 / 42}$ (Harada and Kuroda, 2011) showed that $A \beta$ peptides themselves have a strong tendency to form $\beta$-sheet rich structures during the transition to condensed phases, even without the help of a special effect of hydrophobichydrophilic interface. 
Previously, we reported structures (Streltsov et al., 2004) of the Ig new antigen receptors (IgNARs) from sharks-a distinct class of immune receptors in which antigen binding is encapsulated within a single Ig domain of $13-15 \mathrm{kDa}$ in size (Nuttall et al., 2000). The crystallographic structures of the IgNAR single variable domain (Streltsov et al., 2004) revealed extended $\beta$-hairpin CDR3 loop regions. We hypothesized that engineering the "amyloidogenic" component of $A \beta$ peptide $\left(A \beta_{17-42}\right)$, equivalent to the naturally occurring $3 \alpha / \gamma$-secretase fragment of APP, within this loop would (1) allow formation of an oligomeric structure, while (2) preventing uncontrolled amyloid fibril formation by trapping the amyloidogenic region in a cage of IgNAR domains that was amenable to crystallization. Since the $\beta$-conformation of the $\mathrm{A} \beta \mathrm{p} 3$ region is expected to be formed spontaneously in the oligomeric form, it was allowed and constrained within the region of $\beta$-conformation stabilized by IgNAR tertiary structure. We assumed that the conformation of $\mathrm{A} \beta \mathrm{p} 3$ at boundaries connected to IgNAR should be close to the native. To verify this hypothesis, we solved a $2.05 \AA$ resolution crystal structure obtained using such a strategy and describe strong correlations of our structure with independently observed features of small nonfibrillar $\mathrm{A} \beta$ oligomers.

\section{Materials and Methods}

Construction of A $\beta$-IgNAR chimeras. The A $\beta$ Leu17-Ala42 loop derived from NMR studies (Lührs et al., 2005) was modeled onto the IgNAR 12Y-2 template within the CDR3 loop region (supplemental Fig. S1 $A, B$, available at www.jneurosci.org as supplemental material). For $\mathrm{A} \beta$ IgNAR-G1, note replacement of A $\beta$ Ala42 with glycine, which modeling suggested was required to allow sufficient rotational freedom for realignment of the loop structure. $A \beta$-IgNAR gene constructs were produced by splice-overlap PCR as previously described (Henderson et al., 2007) using IgNAR $12 \mathrm{Y}-2$ DNA template and $\mathrm{A} \beta$ oligonucleotide primers (supplemental Table S1, available at www.jneurosci.org as supplemental material). DNA cassettes were cloned into Escherichia coli periplasmic expression vector pGC as described (Henderson et al., 2007).

Biological and biophysical assays of A $\beta-I g N A R$ proteins. The $\mathrm{A} \beta_{18-41}$ form captured within our constructs and structure represents the $\mathrm{p} 3$ $\alpha / \gamma$-secretase fragment of APP. Attempted standard cell toxicity assays, including tests for inhibition of long-term potentiation showed little evidence of neuronal toxicity for dimers/tetramers of our protein constructs. We attributed this lack of toxicity to (1) the steric hindrance from the surrounding IgNAR domain scaffolding, which renders the dimeric form unable to interact with the neuronal cell membrane, and (2) the lack of the reactive oxygen species toxicity-mediating $\mathrm{N}$-terminal metalbinding $\mathrm{A} \beta_{1-16}$ domain, with the consequence that no reactive oxygen species generation could occur.

Dynamic light scattering (DLS) measurements were done for $\mathrm{A} \beta$ IgNAR-G1 using Zetasizer Nano ZS (Malvern Instruments) instruments at the Bio21 Collaborative Crystallisation Centre. Hydrodynamic radius was calculated from translation diffusion coefficient by the Stokes-Einstein relationship. The fit yields the hydrodynamic radii of $\sim 2.4 \mathrm{~nm}$ of the predominant by mass species in solution.

Protein purification and crystallization. Recombinant proteins (supplemental Table S1, available at www.jneurosci.org as supplemental material) were expressed into the E. coli periplasmic space and purified by affinity chromatography through an anti-FLAG Ig/Sepharose column $(10 \times 1 \mathrm{~cm})$ equilibrated in TBS. Affinity-purified proteins were analyzed by SDS-PAGE, N-terminal sequencing, mass spectrometry, and size exclusion chromatography (FPLC) on a precalibrated Superdex 200 column (GE Healthcare) in $20 \mathrm{~mm}$ Tris $\cdot \mathrm{HCl}, \mathrm{pH}$ 8.0, buffer. Small-scale cultures for Western blot analysis were grown as above, at 28 or $37^{\circ} \mathrm{C}$, purified, and transferred to nitrocellulose membrane. Blots were probed using anti-FLAG monoclonal primary, and goat anti-mouseHRP conjugate secondary antibodies, and then developed using the enhanced chemiluminescent reagent (ECL) (GE Healthcare). Recombinant proteins were collected as single peaks from gel filtration,

\section{Table 1. Data collection and refinement statistics}

\begin{tabular}{ll}
\hline & $A \beta$-IgNAR \\
\hline Data collection & \\
Space group & $P_{2}$ \\
Cell dimensions & \\
$\quad a=b, c(\AA)$ & $79.65,85.46$ \\
$\alpha=\beta, \gamma\left({ }^{\circ}\right)$ & 90,120 \\
Resolution $(\AA)$ & $26.07-2.05(2.09-2.05)^{a}$ \\
$R_{\text {merge }}$ & $0.068(0.928)$ \\
$I / \sigma l$ & $24.1(2.0)$ \\
Completeness $(\%)$ & $100.0(100.0)$ \\
Redundancy & $10.7(7.8)$ \\
Refinement & \\
Resolution $(\AA)$ & $26.07-2.05(2.09-2.05)$ \\
No. reflections & 35,851 \\
$R_{\text {work }} / R_{\text {free }}$ & $0.190 / 0.249$ \\
No. & \\
$\quad$ Protein amino acids & 504 \\
$\quad$ Water & 562 \\
$B$-factors & \\
Protein & 28.31 \\
$\quad$ Water & 39.19 \\
rmsd values & \\
Bond lengths $(\AA)$ & 0.011 \\
Bond angles $\left({ }^{\circ}\right)$ & 1.306 \\
\hline
\end{tabular}

${ }^{a}$ Values in parentheses are for highest-resolution shell.

concentrated to $\sim 4-5 \mathrm{mg} / \mathrm{ml}$ in $20 \mathrm{~mm}$ Tris $\cdot \mathrm{HCl}, \mathrm{pH} 8.0$, and set up as $0.4 \mu \mathrm{l}$ hanging drops around 192 conditions at the Bio21 Collaborative Crystallisation Centre. Plates were incubated at $20^{\circ} \mathrm{C}$. $\mathrm{A} \beta$ IgNAR-G1 crystallized readily under a wide range of conditions [biased toward polyethylene glycol (PEG) 6000 and PEG 3350 at neutral $\mathrm{pH}$ ]. Final crystallization conditions for the best data set were 0.2 M ammonium chloride, 20\% PEG 6000, 0.1 M MES, pH 6, with diffraction quality crystals obtained after $9 \mathrm{~d}$ (see Fig. $1 A$ ). No crystals were obtained for $\mathrm{A} \beta$-IgNAR-G3 or A $\beta$-IgNAR-G6.

Crystallographic data collection, structure determination, and refinement. A full data set (100\% completeness) was collected at the Australian Synchrotron MX1 beam line up to $2.05 \AA$ resolution. Data were collected at $-160^{\circ} \mathrm{C}$ with radiation wavelength of $0.95664 \AA$ and processed using the HKL2000 suite (Otwinowski and Minor, 1997). The structure was solved by molecular replacement MOLREP (Vagin and Teplyakov, 1997) using IgNAR 12Y-2 (PDB 1VES) with removed CDR3 region as search template. Four independent molecules (A-D) were found in the asymmetric unit. The $3 \sigma$ residual electron densities were well defined for the $\mathrm{A} \beta_{18-41}$ (IgNAR 88-111) "CDR3" regions for A and C chains and sufficiently defined for chains $\mathrm{B}$ and $\mathrm{D}$ molecules. The missing parts of the structure $\left(\mathrm{A} \beta_{18-41}\right)$ were built in to that density manually using XtalView (McRee, 1999) and refined with REFMAC5 (Murshudov et al., 1997). Progress of the refinement was monitored using the $R_{\text {free }}$ statistics (Brünger, 1992) based on a set encompassing $5 \%$ of the observed diffraction amplitudes. After the convergence in standard REFMAC5 refinement, additional improvement of $R$ factors ( $>2 \%$ reduction) was achieved by refining all chains as separate rigid anisotropic domains with the TLS procedure (Winn et al., 2001). The final refinement converged to $R / R_{\text {free }}$ values of $0.190 / 0.249$. In total, $99.2 \%$ residues are in preferred and $0.4 \%$ in allowed regions of the Ramachandran plot. Additional details are presented in Table 1. Representative regions of electron density are shown in supplemental Figure S6 (available at www.jneurosci.org as supplemental material). For comparison with DLS measurement, the radii of gyration $\left(R_{\mathrm{g}}\right)$ of $1.56,2.55$, and $2.90 \mathrm{~nm}$ for A $\beta$-IgNAR-G1 monomer $(\mathrm{A})$, dimer $(\mathrm{AC})$, and tetramer $(\mathrm{ABCD})$, respectively, were calculated using MOLREP from refined atomic coordinates. Graphics were created using PyMol (DeLano, 2002) and VMD (Humphrey et al., 1996), and rendered using POV-Ray. Surface area buried by the complex was calculated using the CCP4/ariamol program with a $1.7 \AA$ probe radius and standard van der Waals radii. Calculations of surface complementarity (Sc) were as described previously (Lawrence and Colman, 1993). Coor- 


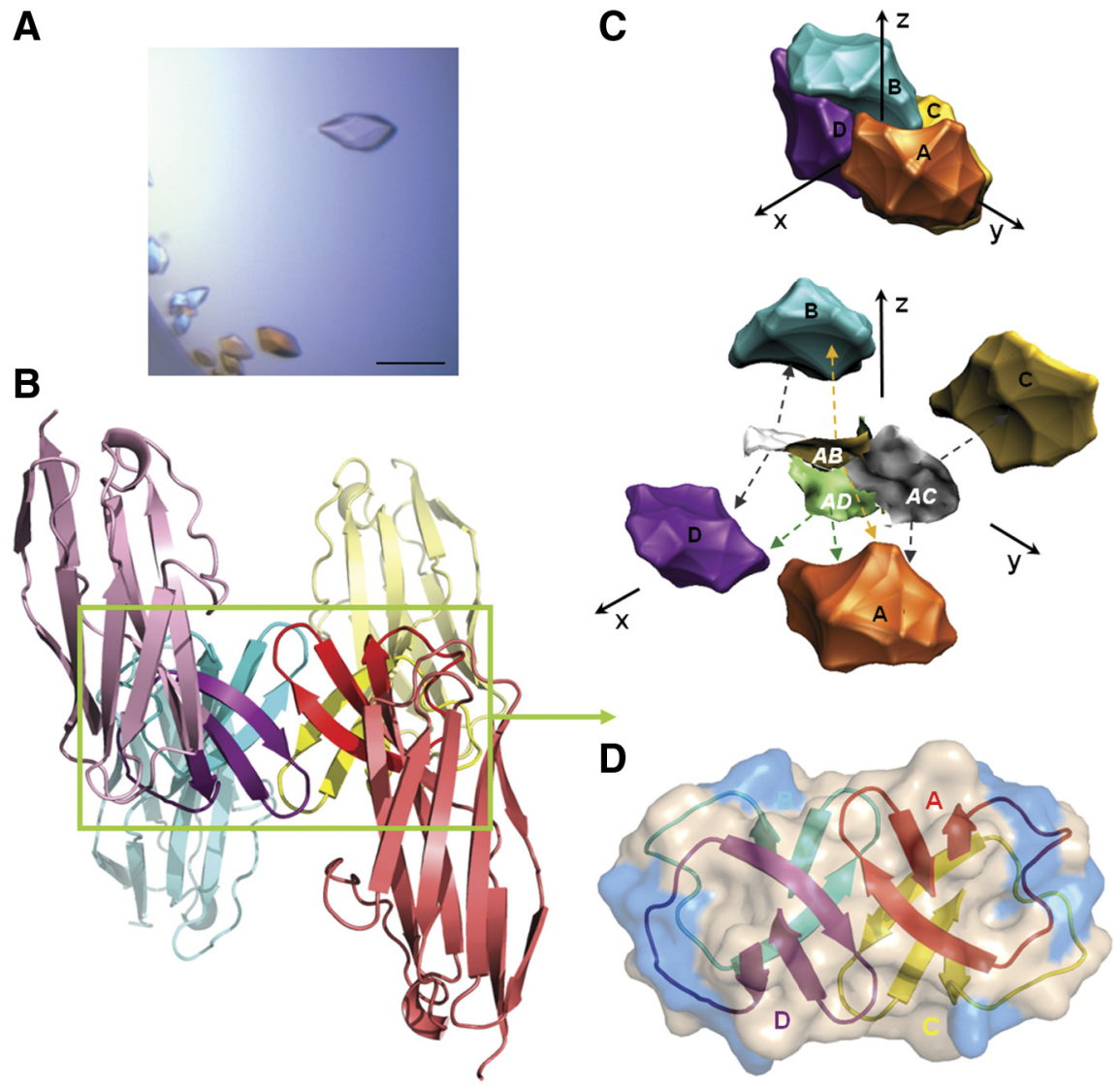

Figure 1. Crystal structure of the $A \beta$-IgNAR-G1 tetramer. $A, A \beta$-IgNAR-G1 crystallized under a wide variety of conditions, in this instance $200 \mathrm{~mm}$ TMAO (trimethylamine N-oxide), $100 \mathrm{~mm}$ Tris, pH 8.5, 20\% PEG MME (monomethyl ether) 2000. Scale bar, $100 \mu \mathrm{m}$. $\boldsymbol{B}$, Diagram representation of four IgNAR domains (color washed) caging $A \beta$ (in rectangular box). $\boldsymbol{C}, A \beta$ tetramer interaction surfaces. $\boldsymbol{D}$, The four $A \beta$ chains (A-D) interact across six $\beta$-sheet structures. Semitransparent solubility surface is shown as hydrophilic (marine blue) and hydrophobic (light pink) areas.

dinates and structure factors have been deposited in the Protein Data Bank under accession numbers 3MOQ.

\section{Results}

\section{A $\beta$-IgNAR protein fusions}

Three chimeric proteins were modeled based on existing NMR $\beta$-hairpin models of amyloid fibril repeats (Lührs et al., 2005), incorporating variable $\mathrm{N}$ - and $\mathrm{C}$-terminal glycine linkers to allow in-register transition from the Ig framework $\beta$-sheets to the $\mathrm{A} \beta$ peptide (supplemental Fig. S1 A, B, Table S1, available at www. jneurosci.org as supplemental material). These constructs, designated $A \beta$-IgNAR-G1, $A \beta$-IgNAR-G3, and A $\beta$-IgNAR-G6, were expressed as recombinant proteins in E. coli and tested for oligomer formation. Dimers stable to SDS and $\beta$-mercaptoethanol, like minimal neurotoxic $\mathrm{A} \beta$ species (Shankar et al., 2008), were observed in the bacterial periplasmic space by Western blot analysis for all three chimeric proteins but not the unmodified IgNAR (supplemental Fig. S1C, available at www.jneurosci.org as supplemental material). The increased conformational flexibility in the glycine- 3 and glycine- 6 versions appeared to allow more rapid dimer formation, and protein induction at higher temperature tended to promote a higher dimer/monomer ratio. On affinity purification, all three variants behaved as dimers, rather than the monomer observed for the wild-type IgNAR, and tetrameric species were also apparent (supplemental Fig. S1D,E, available at www.jneurosci.org as supplemental material).

\section{Crystallization and structure} determination of $A \beta$-IgNAR Crystals of $A \beta$-IgNAR-G1, but not the other two chimeric proteins, grew under a variety of conditions (Fig. 1A). The crystal structure was solved to $2.05 \AA$ resolution by molecular replacement using IgNAR 12Y-2 (PDB 1VES) as search template. Four independent molecules $(\mathrm{A}-\mathrm{D})$ were found in the asymmetric unit, which formed a tight tetramer through interactions completely different to weaker interactions previously observed in the $12 \mathrm{Y}-2$ IgNAR domain (Streltsov et al., 2004).

\section{Quaternary A $\beta$-IgNAR structure}

The A $\beta$-IgNAR-G1 quaternary structure consists of four independent molecules (A-D) in the asymmetric unit (Fig. $1 B$ ), which form a tight homo-tetramer (dimer of dimers) through interactions mediated by the $\mathrm{A} \beta$ peptide component (Fig. 1C). The interchain association for each dimer (A-C and B-D) is extremely robust, as indicated by an average surface of interaction (buried surface) of $580 \AA^{2}$ per monomer and an average shape correlation statistic of 0.64 (supplemental Table S2, available at www.jneurosci.org as supplemental material). The dimer-dimer interaction (AC-BD), which forms the tetramer, is somewhat less extensive (buried surface of $546 \AA^{2}$ per monomer). The comparison of buried surface attributable to $\mathrm{A} \beta$ contacts only ( $1056 \AA^{2}$ per monomer) with the total contact area of $1499 \mathrm{~A}^{2}$ including all crystal contacts suggests that the $\mathrm{A} \beta_{18-41}$ loop contacts $(\sim 70 \%$ of total contact area) are the major contributors to the conformational changes in the $\mathrm{A} \beta$ loops of the $\mathrm{A} \beta$-IgNAR-G1, compared with the crystal contacts between IgNAR scaffolds. The estimate from dynamic light scattering of the hydrodynamic radius of the predominant (by mass) species in solution is $\sim 2.4 \mathrm{~nm}$, which is very close to the predicted $R_{\mathrm{g}}$ of $2.5 \mathrm{~nm}$ for the crystal dimer (AC). This further suggests that the overall fold and size of the $A \beta$ IgNAR dimer, mainly determined by $\mathrm{A} \beta_{18-41}$ conformation and contacts, is preserved in the crystal form.

\section{Structure of A $\beta$-IgNAR monomer}

Excluding the fused $\mathrm{A} \beta_{18-41}$ ("CDR3") regions, the rest of the IgNAR monomer structure is essentially identical with that described for 12Y-2 (Streltsov et al., 2004). The IgNAR chains are overlaid very closely as shown in supplemental Figure S2 A (available at www.jneurosci.org as supplemental material) with an average root mean square deviation (rmsd) of $0.68 \AA^{2}$ for $\mathrm{C}_{\alpha} \mathrm{s}$. The main deviations between chains are in the $\mathrm{A} \beta$ region.

\section{Structure of $\mathrm{A} \boldsymbol{\beta}_{18-41}$ region}

Unexpectedly, the $\mathrm{A} \beta$-IgNAR-G1 structure (Fig. 2) revealed $\mathrm{A} \beta_{18-41}$ as comprising two adjacent and connected loop motifs, rather than the expected extended $\beta$-hairpin structure observed in the IgNAR CDR3 region. The first motif consists of residues Val18-Ile31, which adopts a 10 - to $11-\AA$-wide $\beta$ - $\alpha$ structure, 
stabilized by intramolecular and intermolecular contacts and consisting of one $\beta$-strand (Val18-Ala21) plus a $3_{10}$-helical turn (Val24-Ser26) (chains A and B) or an extended loop (chains $\mathrm{C}$ and $\mathrm{D}$ ). A similar Asp23-Asn27 helix has been predicted from long molecular dynamics simulation models (Rauk, 2008). The second motif consists of residues Ile32-Ile41 and is a $\beta$-hairpin consisting of two antiparallel $\beta$-strands, which form a threestrand $\beta$-sheet, incorporating the parallel $\beta$-strand of the first loop motif. This three-strand antiparallel $\beta$-sheet consists of 16 residues of $\mathrm{A} \beta$ and 5 residues of IgNAR at the protein fusion point, and is strongly stabilized by interstrand interactions across $\mathrm{A} \beta$ dimer and tetramer interfaces.

Importantly, the divergence between residues Val24-Asn27 results in two different conformations for the Lys28 side chain (Fig. 2A). For $\mathrm{A} / \mathrm{B}$, it is directed out of the plane of the loop, forming intramolecular contacts with the main-chain carbonyl oxygen of Val24 (2.6 $\AA$ ) and the side-chain oxygen of Asn27 (3.6 $\AA$ ) of chain A, and helps maintain the helical conformation of Val24-Ser26. Conversely, for C/D, it is directed internally, forming two intramolecular contacts with the carbonyl oxygens of Asp23 (3.0 and $3.5 \AA$ ) and Ser26 (4.0 and 3.0 $\AA$ ), and two intermolecular contacts with the carbonyl oxygens of chain A/B Gly29 (2.6 and $3.3 \AA$ ) and A/B Asn27 (2.8 and $3.6 \AA$ ) (Fig. $2 B$ ). This transition appears pivotal to crystallization, and may represent a vital mechanism (and energy minimum) for $\mathrm{A} \beta$ oligomer formation. In NMR-based structures of amyloid plaques, residues Leu17-Ala42 form parallel, in-register $\beta$-sheets (Petkova et al., 2002; Lührs et al., 2005; Sato et al., 2006), with Lys28 facing outward in the first $A \beta$ chain of the adjacently stacked peptides, whereas subsequent $\mathrm{A} \beta$ peptides have this side chain directed internally and forming intermolecular contacts (salt bridges) with residue Asp23 (Lührs et al., 2005; Petkova et al., 2006; Sato et al., 2006). NMR with mass spectroscopy (Grant et al., 2007) also indicate that Val24-Lys28 and Asp23-Lys28 interactions play an important role in the stabilization of a turn in the $\mathrm{A} \beta_{21-30}$ segment, which nucleates the folding of $A \beta$. Cross-linking of soluble forms of $\mathrm{A} \beta_{1-40}$ nonfibrillar globulomers affected only the $\mathrm{N}$ terminus and Lys16 but not Lys28, which should therefore be involved in interactions in the interior of globulomers (Barghorn et al., 2005).

Overall, the dimers (AC and $\mathrm{BD}$ ) are stabilized around the Asp23-Ala30 loop by the carbonyl oxygen charges neutralizing the buried Lys 28 amide group and by the amide group of Asp27 forming a hydrogen bonding network with Gly29 and Asp27 from the neighboring dimer (Fig. $2 B$ ). The $\beta$-hairpins (amino acids 32-41) from four chains of $A \beta$ form the hydrophobic core of the tetramer (Figs. 1,2) interacting in an antiparallel manner between dimers forming six-strand $\beta$-sheets between the A-B and $\mathrm{C}-\mathrm{D}$ chains from each side of the tetramer (separated by $\sim 6.9-9.7 \AA$ at the central part of the hydrophobic core). The surface toward the tetramer interface is stabilized by hydrophobic residues Ile31, Val40, and Leu34. The Leu34 side chains face each other: two from each side of the tetramer, rotated by $\sim 90^{\circ}$ (see below) (Fig. 3). The close proximity of interchain Leu34 was also observed in the NMR study of soluble oligomers (Yu et al., 2009). Similarly, the respective Met35 side chains are surrounded by
B

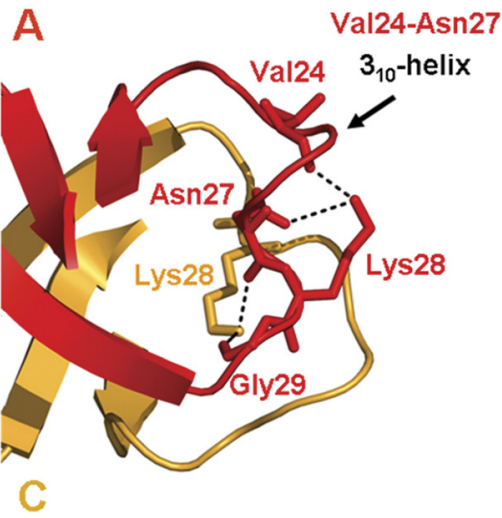

hydrophobic residues Ile32, Val39, and He41. Thus, the effectively hydrophilic loops at position 22-30 (EDVGSNKGA) (Munter et al., 2007) are exposed on the surface of the tetramer, and the remaining mostly hydrophobic parts form $\beta$-sheets in the core of the tetramer. It is perhaps worth mentioning that the $\mathrm{A} \beta_{18-41}$ fragment and, in particular, the $\beta$ - $\alpha$ loop sequence forming the dimer interface, is modulated by three GxxxG motifs (G25xxxG29xxxG33xxxG37). Such motifs, attributable perhaps to the small size of the glycine residues, have previously been shown to promote close packing and dimerization of the APP juxtamembrane and transmembrane regions (Barnham et al., 2006; Munter et al., 2007; Kienlen-Campard et al., 2008).

Intermolecular contacts observed by NMR such as Ala21/ Val36 (Lührs et al., 2005) and Ile32/Leu34/Val36 (Petkova et al., 2006; Yu et al., 2009) are also observed. However, the Val36 of chain A is facing the Ala21 and Leu34 of chain B (side-chain separations of 3.8 and $4.5 \AA$, respectively) across the tetramer central core and is also involved in the hydrogen bond of $2.8 \AA$ between $\mathrm{N}(\mathrm{Val} 36)$ and $\mathrm{O}($ Ile32) of the antiparallel $\beta$-sheet formed by chains A and D. These contacts between the two juxtaposed and oppositely oriented peptides in the protofilament have been proposed in paired $\beta$-sheet structures of $\mathrm{A} \beta_{1-40}$ (Sachse et al., 2008). An earlier crystallographic structure of $A \beta_{28-42}$ C-terminally fused to Tk-RNase HII (Takano et al., 2006) also suggested formation of a limited $\beta$-hairpin conformation which overlaps with the A $\beta$-IgNAR-G1 $\beta$-hairpin motif (rmsd, $1.9 \AA$ ) (supplemental Fig. S2 B, $C$, available at www.jneurosci.org as supplemental material). The whole $A \beta_{18-41}$ tetramer has approximately scalene ellipsoid shape with $\sim 27 \times 39 \AA$ equatorial (interface of the A-C and B-D dimers) and polar $\sim 18 \AA$ dimensions. These dimensions are compatible with neuronal plasma membrane thickness (lipid bilayer of $\sim 30-50 \AA$ with hydrocarbon layer of $\sim 19-30 \AA$ ) (Rand, 1971) as well as with the average size of $\sim 46 \AA$ estimated from hydrodynamic properties of fluorescently labeled $A \beta_{1-40}$ oligomers on and above the membrane of cultured PC12 cells at near-physiological concentrations (Nag et al., 2010).

\section{Mutations in $\mathrm{A} \boldsymbol{\beta}_{18-41}$ region}

Familial and in vitro-generated mutations represent valuable tools for dissecting $\mathrm{A} \beta$ peptide function. For example, the major pathogenic familial AD mutations (Betts et al., 2008) Ala21Gly (Flemish), Glu22Gly (Arctic), Glu22Gln (Dutch), Glu22Lys (Italian), and Asp23Asn (Iowa) are localized within the $\beta$-turn 
A
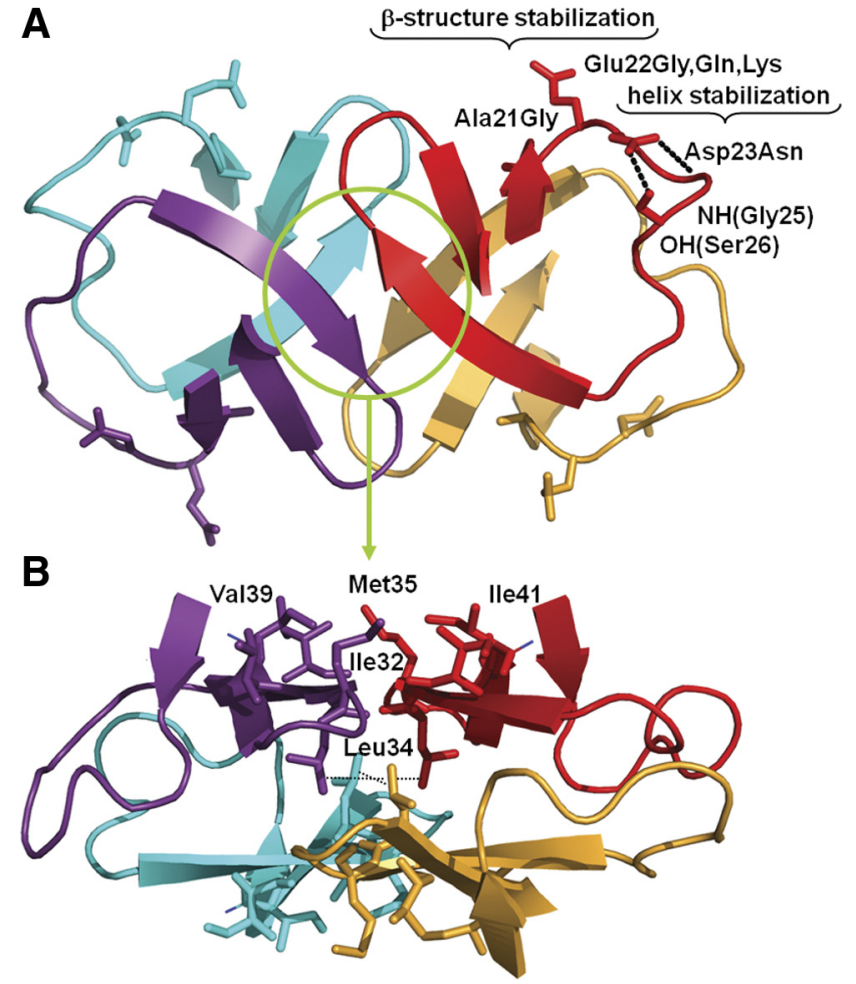

Figure 3. Correlation with familial AD and in vitro mutation data. $A$, Residues Ala21, Glu22, and Asp23 are exposed within a $\beta$-turn. $\boldsymbol{B}$, Residue Leu34 occupies a pivotal position within both the dimer and tetramer interfaces. Hydrophobic residues Ile32, Met35, Val39, and lle41, important in amyloid formation in this model, are shown at the top of the structure.

stabilized by hydrogen bonds between Asp23(OD1) and Ser26(OG) (2.8 $\AA$ ), and Asp23(OD2) and Gly25(N) (3.4 $\AA$ ) (Fig. $3 A$ ). The FAD mutation Asp23Asn is predicted to alter interactions with Phe20 (which is also important for loop stability): Asp23(OD1) is at 2.6 from an intraloop water molecule, which is at $3.1 \AA$ from Phe $20(\mathrm{~N})$. The Glu22Gly/Gln/Lys mutations (Fig. 3A) do not directly affect the structure of the 22-28 loop but rather weaken the interactions between this loop and the central hydrophobic segment (amino acids 18-21), as predicted by molecular dynamic simulations of the $\mathrm{A} \beta_{15-28}$ Glu22Gln mutant, which increases the propensity of the $\beta$-structure in the hydrophobic segment (Baumketner et al., 2008).

Similarly, mutations derived in vitro from studies of $\mathrm{A} \beta_{1-42^{-}}$ GFP (green fluorescent protein) fusions (Wurth et al., 2002) indicate residues important in aggregation. These mutations map to surface residues of the monomer, which we predict will interfere with formation of the dimer or tetramer interfaces and the amylogenic surface. For example, mutation Leu34Pro is described to markedly decrease $\mathrm{A} \beta$ aggregation, both alone and in combination with other variants. In our structure, the four Leu34 side chains form a hydrophobic clamp (Fig. $3 B$ ), leading to our prediction that a Leu34Pro substitution would (1) disrupt the central hydrophobic core of the tetramer and (2) break the $\beta$-sheets formed by residues Ile32-Val36 between adjacent dimers. The close proximity of Leu34 residues in oligomeric A $\beta$ has been also shown by the NMR study of the A $\beta_{1-42}$ Leu34Cys mutant with an engineered disulfide bond, which exhibited properties identical with wild type (Yu et al., 2009). To test this theory, we produced the variant A $\beta$-IgNAR-G1 (Leu34Pro) and assessed the effect of this change on dimerization. We observed marked reversion to monomeric form of similar magnitude $(\sim 30 \%)$ to that originally described for this mutation in vitro (Wurth et al., 2002). On affinity purification, this variant tended toward dimerization, but in contrast to the parental $\mathrm{A} \beta$ IgNAR-G1 was not resistant to $\beta$-mercaptoethanol treatment (supplemental Fig. S3 $A, B$, available at www.jneurosci.org as supplemental material) and failed to crystallize, suggesting that the tetramer interface had indeed been compromised. Phe19 is another important residue for stabilizing the dimer since its sidechain phenyl ring is inserted in between the Val40 methyl groups and the Ser26 carbonyl group and close (4.3-5.2 $\AA$ ) to the hydrophobic pocket formed by two Ile 31 side chains ( $4 \AA$ apart) from the same monomer and across the dimer interface (supplemental Fig. S3C, available at www.jneurosci.org as supplemental material). The single mutation Phe19Ser or combined with Ser26Phe and Val40Leu, or combined with Leu34Pro, has been reported to compromise significantly up to 24 or $34 \%$, or $100 \%$ the folding and assembly of $A \beta$ oligomers (Wurth et al., 2002). Interestingly, a seeded growth of $\mathrm{A} \beta$ fibrils from $\mathrm{AD}$ brain-derived fibrils produced a distinct and toxic fibril structure, which showed the formation of Phe19-Ile31 side-chain contacts (Paravastu et al., 2009). This was not observed in synthetic fibrils.

\section{A model of multimeric oligomers}

Our tetrameric structure displays features described for various models of both A $\beta$ protofilaments (Malinchik et al., 1998; Losic et al., 2006) and soluble globulomers (Barghorn et al., 2005) and shows strong correlation with other independently obtained structural data for $\mathrm{A} \beta$ fragments and fibrils. Conversely, our structure is somewhat different from the dimer-like model of the $\mathrm{A} \beta$ nonfibrillar globulomer repeat proposed from NMR data $(\mathrm{Yu}$ et al., 2009). Although a model of globulomer (12- to 14-mers) based on that dimer-like unit was not predicted (and seems not trivial), it was indicated that with globulomer formation only the last 31-42 residues were fully protected in amide exchange measurements (Yu et al., 2009). The top and bottom of our tetramer are covered by a contiguous hydrophobic surface formed by residues 18-21 and 31-41 with a girdle of hydrophilic residues (amino acids 22-30) running along the sides. Thus, we hypothesized that the observed dimer or tetramer may be a common structural motif in $A \beta$ oligomerization, and we modeled the $A \beta$ tetramers minus the IgNAR domain as a building block of higher order oligomers. By aligning $\mathrm{A} \beta$ tetramers on top of each other along the polar axis, using the hydrophobic surface and the interaction pattern observed between parallel $\mathrm{A} \beta$ stacks by NMR structure (Petkova et al., 2006) (Fig. 4A; supplemental Fig. S4A, available at www.jneurosci.org as supplemental material), a series of multimeric constructs were generated (Fig. $4 B$ ). Sequential tetramers in this model are rotated by $\sim 30^{\circ}$ along the oligomer axis creating a twisted (coiled) cylinder up to $\sim 40 \AA$ wide. Elongated protofibrils with some features close to our model have been recently predicted by simulated oligomer formation using DMD (discrete molecular dynamics) with a four-bead protein model (Urbanc et al., 2010).

Adding $\mathrm{N}$-terminal A $\beta$ peptide residues Asp1-Lys 16 [containing the high-affinity metal-binding site, as described by $\mathrm{x}$-ray absorption spectroscopy (Streltsov et al., 2008)] onto the crystallographic tetramer results in a model whereby this unstructured metal-binding fragment is ideally oriented to mediate reactive oxygen species toxicity (Fig. 4C; supplemental Fig. S4 B, available at www.jneurosci.org as supplemental material). Mechanistically, neighboring tetramers align Glu22 and Asp23 side chains (from different tetramers colored red in Fig. $4 B$ ) to form a belt of potential metal-binding sites (Glu22Glu22 = 10-12 A; Asp23-Asp23 = 5.5-7 $)$ ). With contributions 
A

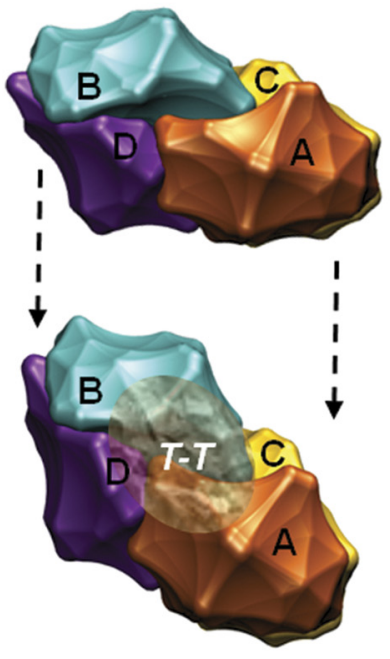

B

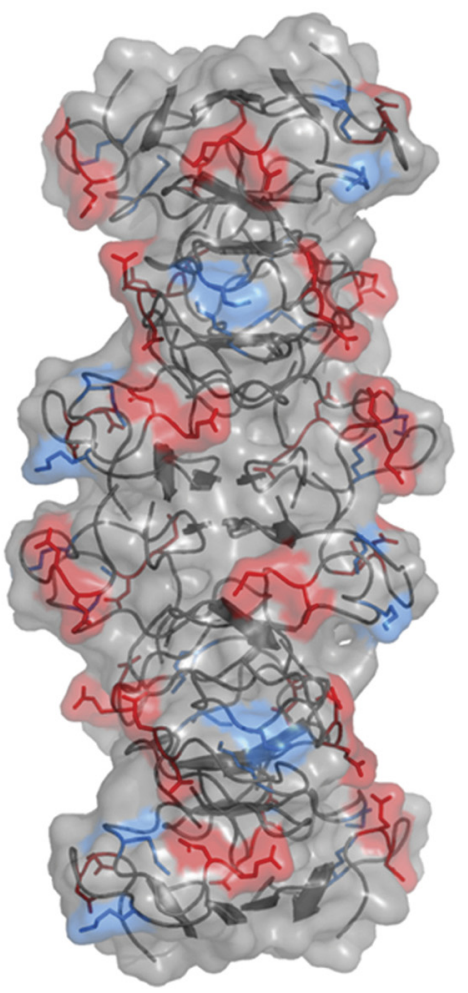

C
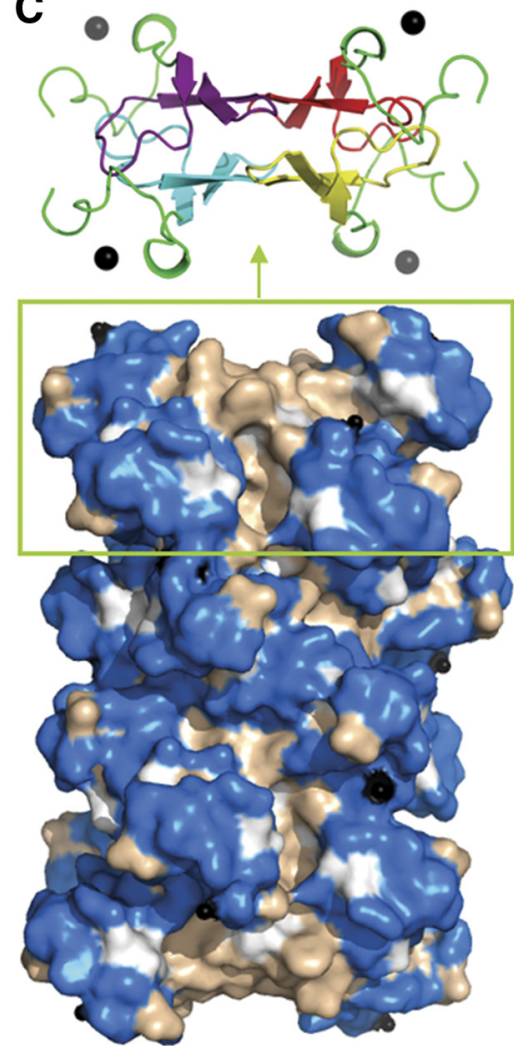

Figure 4. Models of amyloid multimeric oligomer formation. $A$, Assembly of the $A \beta$ oligomer from two tetramers with the $T-T$ interface. $B, A \beta$ oligomer model based on six $A \beta_{18-41}$ tetramers. Overlaid surfaces highlight negatively charged (red) and positively charged (blue) residues. $\boldsymbol{C}$, As for $\boldsymbol{A}$ and $\boldsymbol{B}$, incorporating $A \beta_{1-17}$ metal-binding regions (solubility surfaces: marine blue, hydrophilic; light pink, hydrophobic). The black spheres represent metals ( $\mathrm{Zn}$, $\mathrm{Cu}$, etc.). The $\mathrm{N}$-terminal $\mathrm{A} \beta_{1-17}$ is in green in the inset diagram.

from oxygen and nitrogen atoms, this, conceivably, may produce one additional metal-binding site per $\mathrm{A} \beta$ monomer in the aggregate (Caine et al., 2007). On metal binding to the $\mathrm{A} \beta \mathrm{N}$ terminus (Asp1; Glu11; His6; His13; His14) (Streltsov, 2008; Streltsov et al., 2008), the adjacent Val18Ala21 fragment should be stabilized, facilitating tetramer-tetramer interactions and accelerating oligomer growth. Conversely, oxidation of Met 35 side chains to the sulfoxides, which are exposed on the surface of the tetramer (Fig. 3), could significantly impede the aggregation of the $\mathrm{A} \beta$ peptide (Hou et al., 2004).

\section{Discussion}

We started with an observation and a hypothesis. It has been shown that $\mathrm{A} \beta$ spontaneously aggregates into $\beta$-sheet-rich oligomers/fibrils resembling those in the $\mathrm{AD}$ brain plaques and the structures of dimers, tetramers, and other low-MW A $\beta$ oligomers were consistent with the model of the $\mathrm{A} \beta$ monomers as $\beta$-hairpins. However, we earlier observed that the $12 \mathrm{Y}-2$ IgNAR single domain antibody crystal structures comfortably accommodated the extended antigenbinding $\beta$-hairpin CDR3 loop. We then hypothesized that engineering the "amyloidogenic" $\mathrm{p} 3$ region of $\mathrm{A} \beta$ peptide con-

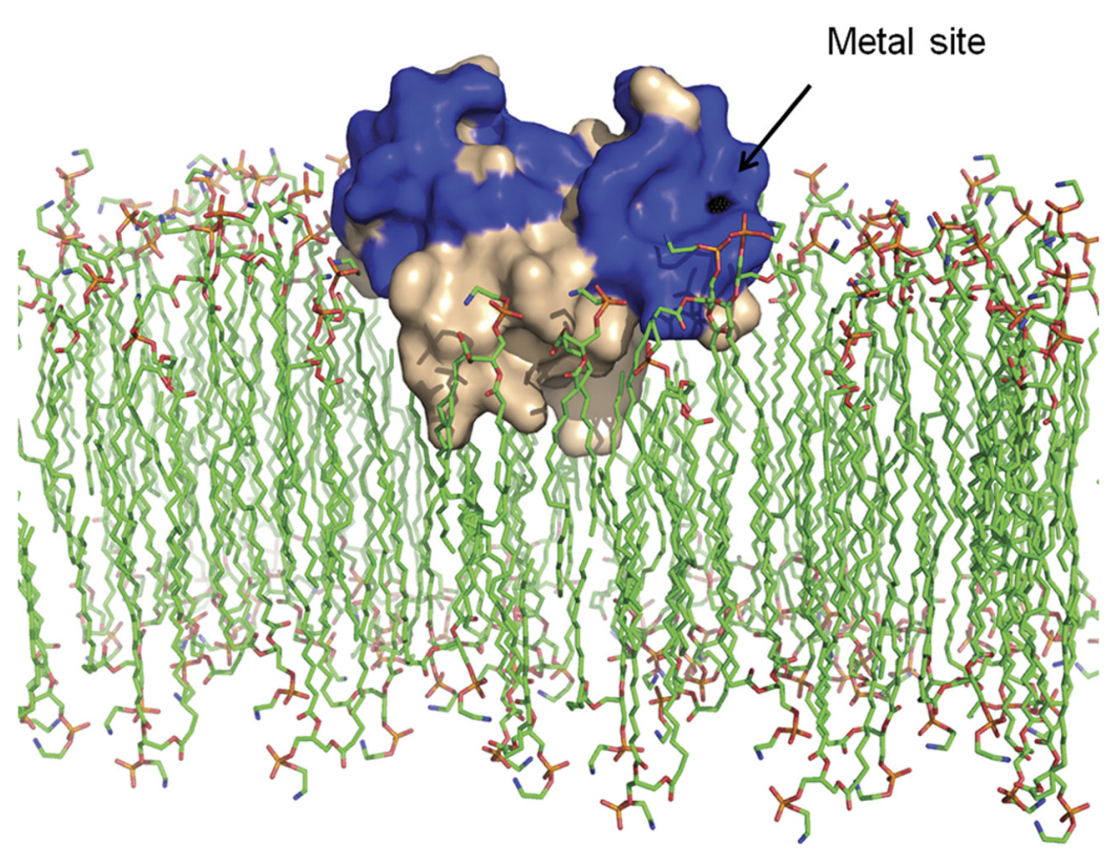

Figure 5. Model of potential interactions of $A \beta_{18-41}$ dimer with membrane lipid bilayers. The hydrophobic dimer-dimer interface of the $A \beta_{18-41}$ tetramer is intercalated into the membrane surface through nonelectrostatic interactions, whereas hydrophilic aspects (blue) with metal-binding sites (black) are on the membrane surface.

strained within this loop region would cage the peptide, prevent uncontrolled oligomerization, and allow crystallization. Our results vindicated this hypothesis and, surprisingly, revealed not the expected $\beta$-turn- $\beta$ extended loop but rather compact struc- 
ture, which forms a tight dimer in solution and a tetramer (dimer of dimers) as the oligomeric unit in the crystal. This may prove to be one of the possible nonfibrillar oligomeric building block and is, to the best of our knowledge, the first full $\mathrm{x}$-ray crystallographic structure of $\mathrm{A} \beta_{18-41}$ fragment.

Detailed structural characterization of soluble nonfibrillar intermediates has been difficult because they are sensitive to solution preparations. Most of these nonfibril preparations contain $\mathrm{A} \beta$ monomers as well as diverse $\mathrm{A} \beta$ oligomers that may be in dynamic equilibrium with one another. Structurally different oligomers may also represent templates for formation of morphologically diverse $A \beta$ fibrils with different underlying structures (Petkova et al., 2005). A better standardization of A $\beta$ preparations across studies is an important objective (Ryan et al., 2010).

Recent evidence suggests an alternative mechanism of A $\beta$ toxicity mediated by the p3 fragment (Jang et al., 2010) interacting with the neuronal membrane and forming $\mathrm{Zn}$-dependent channels. In such a model, cell membranes appear to act as two-dimensional aggregation templates. For example, complementary CD, NMR, and electron paramagnetic resonance analyses (Grimaldi et al., 2010) performed in SDS and DPC (dodecyl phosphocholine) micelles showed that $\mathrm{A} \beta_{16-35}$ undergoes a conformational transition from a soluble helical structure, to a U-turn-shaped conformation, and fluorescence and CD spectra at varied temperatures (Yoda et al., 2008) show that the flat surface of tightly packed PC (phosphatidylcholine) membranes (a major component of neuronal cell membranes) appears to serve as a platform for nonelectrostatic interactions and self-association. Furthermore, at near-physiological concentrations of $\mathrm{A} \beta$ only the small oligomeric $\mathrm{A} \beta$ species of $\sim 46 \AA$ are relevant, they are capable of attaching to the PC12 cell membrane, and they assemble in situ to form much larger complexes (Nag et al., 2010). Based on our structure modeling of A $\beta$ dimer with the $\mathrm{N}$-terminal $\mathrm{A} \beta_{1-16}$ metal-binding sites (similar to tetramer in supplemental Fig. $\$ 4$, available at www.jneurosci.org as supplemental material) in a membrane environment exposes hydrophilic residues (amino acids $\sim 21-29$, and the N-terminal metalbinding sites) while burying hydrophobic residues involved in dimer-dimer interactions in a hydrophobic milieu (Fig. 5). Similar nonelectrostatic associations with bacterial membranes may be a feature of the proposed antimicrobial function of $\mathrm{A} \beta$ peptide in the innate immune system (Soscia et al., 2010) In a possible convergence scenario, our $\mathrm{A} \beta_{18-41}$ dimer structure ( $\mathrm{A}$ and $\mathrm{D}$ chains) shows striking similarities (supplemental Fig. S5, available at www.jneurosci. org as supplemental material) (Soscia et al., 2010).

Beyond its proposed role as a defense peptide, naturally occurring p3 peptide is a major constituent of Down's syndrome (DS) cerebellar preamyloid (Lalowski et al., 1996) and of selected areas of AD brain diffuse deposits (Higgins et al., 1996). Such deposits (in particular $\mathrm{A} \beta$ homodimers) have been proposed to serve as nidi for plaque formation and represent well defined therapeutic targets (Schmechel et al., 2003). Our structure suggests that such p3 oligomers possess a unique and noncross $\beta$-sheet fold, a result consistent with the observation that $\mathrm{AD}$ diffuse deposits and DS cerebellar preamyloid lesions (formed mainly from p3) are Congo red-negative and mostly ultrastructurally nonfibrillar (Lalowski et al., 1996). In this context, as a molecular target for Alzheimer's disease intervention agents, our structure can be envisaged as presenting three aspects, which we describe as the dimer interface, the tetramer interface, and the amyloid extension face. Each potentially represents a viable binding region for agents aimed at disrupting oligomer formation (and associated toxic activity). Such moieties may extend beyond imaging agents to novel chemical and biological entities, in- cluding chemical compounds, peptidomimetic constructs, and monoclonal antibodies.

\section{References}

Barghorn S, Nimmrich V, Striebinger A, Krantz C, Keller P, Janson B, Bahr M, Schmidt M, Bitner RS, Harlan J, Barlow E, Ebert U, Hillen H (2005) Globular amyloid $\beta$-peptide oligomer-a homogenous and stable neuropathological protein in Alzheimer's disease. J Neurochem 95:834-847.

Barnham KJ, Cappai R, Beyreuther K, Masters CL, Hill AF (2006) Delineating common molecular mechanisms in Alzheimer's and prion diseases. Trends Biochem Sci 31:465-472.

Baumketner A, Krone MG, Shea JE (2008) Role of the familial Dutch mutation E22Q in the folding and aggregation of the 15-28 fragment of the Alzheimer amyloid- $\beta$ protein. Proc Natl Acad Sci U S A 105:6027-6032.

Betts V, Leissring MA, Dolios G, Wang R, Selkoe DJ, Walsh DM (2008) Aggregation and catabolism of disease-associated intra- $\mathrm{A} \beta$ mutations: reduced proteolysis of A $\beta A 21 \mathrm{G}$ by neprilysin. Neurobiol Dis 31:442-450.

Brünger AT (1992) Free R value: a novel statistical quantity for assessing the accuracy of crystal structures. Nature 355:472-475.

Caine J, Volitakis I, Cherny R, Varghese J, Macreadie I (2007) A $\beta$ produced as a fusion to maltose binding protein can be readily purified and stably associates with copper and zinc. Protein Pept Lett 14:83-86.

Chimon S, Ishii Y (2005) Capturing intermediate structures of Alzheimer's $\beta$-amyloid, $\mathrm{A} \beta(1-40)$, by solid-state NMR spectroscopy. J Am Chem Soc 127:13472-13473.

Chimon S, Shaibat MA, Jones CR, Calero DC, Aizezi B, Ishii Y (2007) Evidence of fibril-like $\beta$-sheet structures in a neurotoxic amyloid intermediate of Alzheimer's $\beta$-amyloid. Nat Struct Mol Biol 14:1157-1164.

DeLano WL (2002) The PyMOL molecular graphics system. San Carlos, CA: DeLano Scientific.

Egnaczyk GF, Greis KD, Stimson ER, Maggio JE (2001) Photoaffinity crosslinking of Alzheimer's disease amyloid fibrils reveals interstrand contact regions between assembled $\beta$-amyloid peptide subunits. Biochemistry 40:11706-11714.

Gardberg AS, Dice LT, Ou S, Rich RL, Helmbrecht E, Ko J, Wetzel R, Myszka DG, Patterson PH, Dealwis C (2007) Molecular basis for passive immunotherapy of Alzheimer's disease. Proc Natl Acad Sci USA 104:15659-15664.

Grant MA, Lazo ND, Lomakin A, Condron MM, Arai H, Yamin G, Rigby AC, Teplow DB (2007) Familial Alzheimer's disease mutations alter the stability of the amyloid $\beta$-protein monomer folding nucleus. Proc Natl Acad Sci U S A 104:16522-16527.

Grimaldi M, Scrima M, Esposito C, Vitiello G, Ramunno A, Limongelli V, D'Errico G, Novellino E, D'Ursi AM (2010) Membrane charge dependent states of the $\beta$-amyloid fragment $\mathrm{A} \beta(16-35)$ with differently charged micelle aggregates. Biochim Biophys Acta 1798:660-671.

Harada T, Kuroda R (2011) CD measurements of $\beta$-amyloid (1-40) and $(1-42)$ in the condensed phase. Biopolymers 95:127-134.

Henderson KA, Streltsov VA, Coley AM, Dolezal O, Hudson PJ, Batchelor AH, Gupta A, Bai T, Murphy VJ, Anders RF, Foley M, Nuttall SD (2007) Structure of an IgNAR-AMA1 complex: targeting a conserved hydrophobic cleft broadens malarial strain recognition. Structure 15:1452-1466.

Higgins LS, Murphy GM Jr, Forno LS, Catalano R, Cordell B (1996) P3 $\beta$-amyloid peptide has a unique and potentially pathogenic immunohistochemical profile in Alzheimer's disease brain. Am J Pathol 149:585-596.

Hou L, Shao H, Zhang Y, Li H, Menon NK, Neuhaus EB, Brewer JM, Byeon IJ, Ray DG, Vitek MP, Iwashita T, Makula RA, Przybyla AB, Zagorski MG (2004) Solution NMR studies of the $A \beta(1-40)$ and $A \beta(1-42)$ peptides establish that the Met35 oxidation state affects the mechanism of amyloid formation. J Am Chem Soc 126:1992-2005.

Humphrey W, Dalke A, Schulten K (1996) VMD: visual molecular dynamics. J Mol Graph 14:33-38, 27-28.

Jang H, Arce FT, Ramachandran S, Capone R, Azimova R, Kagan BL, Nussinov R, Lal R (2010) Truncated $\beta$-amyloid peptide channels provide an alternative mechanism for Alzheimer's disease and Down syndrome. Proc Natl Acad Sci U S A 107:6538-6543.

Kajava AV, Squire JM, Parry DA (2006) $\beta$-Structures in fibrous proteins. Adv Protein Chem 73:1-15.

Kienlen-Campard P, Tasiaux B, Van Hees J, Li M, Huysseune S, Sato T, Fei JZ, Aimoto S, Courtoy PJ, Smith SO, Constantinescu SN, Octave JN (2008) Amyloidogenic processing but not amyloid precursor protein (APP) intracellular C-terminal domain production requires a precisely oriented 
APP dimer assembled by transmembrane GXXXG motifs. J Biol Chem 283:7733-7744.

Lalowski M, Golabek A, Lemere CA, Selkoe DJ, Wisniewski HM, Beavis RC, Frangione B, Wisniewski T (1996) The "nonamyloidogenic" p3 fragment (amyloid $\beta 17-42$ ) is a major constituent of Down's syndrome cerebellar preamyloid. J Biol Chem 271:33623-33631.

Lawrence MC, Colman PM (1993) Shape complementarity at protein/protein interfaces. J Mol Biol 234:946-950.

Losic D, Martin LL, Mechler A, Aguilar MI, Small DH (2006) High resolution scanning tunnelling microscopy of the $\beta$-amyloid protein $(\mathrm{A} \beta 1-40)$ of Alzheimer's disease suggests a novel mechanism of oligomer assembly. J Struct Biol 155:104-110.

Lührs T, Ritter C, Adrian M, Riek-Loher D, Bohrmann B, Döbeli H, Schubert D, Riek R (2005) 3D structure of Alzheimer's amyloid- $\beta(1-42)$ fibrils. Proc Natl Acad Sci U S A 102:17342-17347.

Lynn DG, Meredith SC (2000) Review: model peptides and the physicochemical approach to $\beta$-amyloids. J Struct Biol 130:153-173.

Malinchik SB, Inouye H, Szumowski KE, Kirschner DA (1998) Structural analysis of Alzheimer's $\beta(1-40)$ amyloid: protofilament assembly of tubular fibrils. Biophys J 74:537-545.

Mastrangelo IA, Ahmed M, Sato T, Liu W, Wang C, Hough P, Smith SO (2006) High-resolution atomic force microscopy of soluble $A \beta 42$ oligomers. J Mol Biol 358:106-119.

McRee DE (1999) XtalView/Xfit-a versatile program for manipulating atomic coordinates and electron density. J Struct Biol 125:156-165.

Miles LA, Wun KS, Crespi GA, Fodero-Tavoletti MT, Galatis D, Bagley CJ, Beyreuther K, Masters CL, Cappai R, McKinstry WJ, Barnham KJ, Parker MW (2008) Amyloid- $\beta$-anti-amyloid- $\beta$ complex structure reveals an extended conformation in the immunodominant B-cell epitope. J Mol Biol 377:181-192.

Munter LM, Voigt P, Harmeier A, Kaden D, Gottschalk KE, Weise C, Pipkorn R, Schaefer M, Langosch D, Multhaup G (2007) GxxxG motifs within the amyloid precursor protein transmembrane sequence are critical for the etiology of A $\beta 42$. EMBO J 26:1702-1712.

Murshudov GN, Vagin AA, Dodson EJ (1997) Refinement of macromolecular structures by the maximum-likelihood method. Acta Crystallogr D Biol Crystallogr 53:240-255.

Nag S, Chen J, Irudayaraj J, Maiti S (2010) Measurement of the attachment and assembly of small amyloid- $\beta$ oligomers on live cell membranes at physiological concentrations using single-molecule tools. Biophys J 99:1969-1975.

Nelson R, Eisenberg D (2006) Recent atomic models of amyloid fibril structure. Curr Opin Struct Biol 16:260-265.

Nuttall SD, Irving RA, Hudson PJ (2000) Immunoglobulin VH domains and beyond: design and selection of single-domain binding and targeting reagents. Curr Pharm Biotechnol 1:253-263.

Otwinowski Z, Minor W (1997) Processing of X-ray diffraction data collected in oscillation mode. Methods Enzymol 276:307-326.

Paravastu AK, Qahwash I, Leapman RD, Meredith SC, Tycko R (2009) Seeded growth of $\beta$-amyloid fibrils from Alzheimer's brain-derived fibrils produces a distinct fibril structure. Proc Natl Acad Sci U S A 106:7443-7448.

Petkova AT, Ishii Y, Balbach JJ, Antzutkin ON, Leapman RD, Delaglio F, Tycko R (2002) A structural model for Alzheimer's $\beta$-amyloid fibrils based on experimental constraints from solid state NMR. Proc Natl Acad Sci U S A 99:16742-16747.

Petkova AT, Leapman RD, Guo Z, Yau WM, Mattson MP, Tycko R (2005) Self-propagating, molecular-level polymorphism in Alzheimer's $\beta$-amyloid fibrils. Science 307:262-265.

Petkova AT, Yau WM, Tycko R (2006) Experimental constraints on quaternary structure in Alzheimer's $\beta$-amyloid fibrils. Biochemistry 45:498-512.

Querfurth HW, LaFerla FM (2010) Alzheimer's disease. N Engl J Med 362:329-344.

Rand RP (1971) Structural studies by X-ray diffraction of model lipidprotein membranes of serum albumin-lecithin-cardiolipin. Biochim Biophys Acta 241:823-834.

Rauk A (2008) Why is the amyloid $\beta$ peptide of Alzheimer's disease neurotoxic? Dalton Trans 10:1273-1282.

Ryan DA, Narrow WC, Federoff HJ, Bowers WJ (2010) An improved method for generating consistent soluble amyloid-beta oligomer preparations for in vitro neurotoxicity studies. J Neurosci Methods 190:171-179.

Sachse C, Fändrich M, Grigorieff N (2008) Paired $\beta$-sheet structure of an A $\beta(1-40)$ amyloid fibril revealed by electron microscopy. Proc Natl Acad Sci U S A 105:7462-7466.

Sato T, Kienlen-Campard P, Ahmed M, Liu W, Li H, Elliott JI, Aimoto S, Constantinescu SN, Octave JN, Smith SO (2006) Inhibitors of amyloid toxicity based on $\beta$-sheet packing of $\mathrm{A} \beta 40$ and $\mathrm{A} \beta 42$. Biochemistry 45:5503-5516.

Sawaya MR, Sambashivan S, Nelson R, Ivanova MI, Sievers SA, Apostol MI, Thompson MJ, Balbirnie M, Wiltzius JJ, McFarlane HT, Madsen AØ, Riekel C, Eisenberg D (2007) Atomic structures of amyloid cross- $\beta$ spines reveal varied steric zippers. Nature 447:453-457.

Schmechel A, Zentgraf H, Scheuermann S, Fritz G, Pipkorn R, Reed J, Beyreuther K, Bayer TA, Multhaup G (2003) Alzheimer $\beta$-amyloid homodimers facilitate $\mathrm{A} \beta$ fibrillization and the generation of conformational antibodies. J Biol Chem 278:35317-35324.

Shankar GM, Li S, Mehta TH, Garcia-Munoz A, Shepardson NE, Smith I, Brett FM, Farrell MA, Rowan MJ, Lemere CA, Regan CM, Walsh DM, Sabatini BL, Selkoe DJ (2008) Amyloid- $\beta$ protein dimers isolated directly from Alzheimer's brains impair synaptic plasticity and memory. Nat Med 14:837-842.

Shen Y, Joachimiak A, Rosner MR, Tang WJ (2006) Structures of human insulin-degrading enzyme reveal a new substrate recognition mechanism. Nature 443:870-874.

Sorimachi K, Craik DJ, Lloyd EJ, Beyreuther K, Masters CL (1990) Identification of a $\beta$-turn in the tertiary structure of a peptide fragment of the Alzheimer amyloid protein. Biochem Int 22:447-454.

Soscia SJ, Kirby JE, Washicosky KJ, Tucker SM, Ingelsson M, Hyman B, Burton MA, Goldstein LE, Duong S, Tanzi RE, Moir RD (2010) The Alzheimer's disease-associated amyloid $\beta$-protein is an antimicrobial peptide. PLoS One 5:e9505.

Streltsov V (2008) X-ray absorption and diffraction studies of the metal binding sites in amyloid $\beta$-peptide. Eur Biophys J 37:257-263.

Streltsov VA, Varghese JN, Carmichael JA, Irving RA, Hudson PJ, Nuttall SD (2004) Structural evidence for evolution of shark Ig new antigen receptor variable domain antibodies from a cell-surface receptor. Proc Natl Acad Sci U S A 101:12444-12449.

Streltsov VA, Titmuss SJ, Epa VC, Barnham KJ, Masters CL, Varghese JN (2008) The structure of the amyloid- $\beta$ peptide high-affinity copper II binding site in Alzheimer disease. Biophys J 95:3447-3456.

Takano K, Endo S, Mukaiyama A, Chon H, Matsumura H, Koga Y, Kanaya S (2006) Structure of amyloid- $\beta$ fragments in aqueous environments. FEBS J 273:150-158.

Tycko R (2001) Solid-state nuclear magnetic resonance techniques for structural studies of amyloid fibrils. Methods Enzymol 339:390-413.

Urbanc B, Betnel M, Cruz L, Bitan G, Teplow DB (2010) Elucidation of amyloid $\beta$-protein oligomerization mechanisms: discrete molecular dynamics study. J Am Chem Soc 132:4266-4280.

Vagin A, Teplyakov A (1997) MOLREP: an automated program for molecular replacement. J Appl Crystallogr 30:1022-1025.

Walsh DM, Selkoe DJ (2007) A $\beta$ oligomers - a decade of discovery. J Neurochem 101:1172-1184.

Winn MD, Isupov MN, Murshudov GN (2001) Use of TLS parameters to model anisotropic displacements in macromolecular refinement. Acta Crystallogr D Biol Crystallogr 57:122-133.

Wurth C, Guimard NK, Hecht MH (2002) Mutations that reduce aggregation of the Alzheimer's A $\beta 42$ peptide: an unbiased search for the sequence determinants of $\mathrm{A} \beta$ amyloidogenesis. J Mol Biol 319:1279-1290.

Yoda M, Miura T, Takeuchi H (2008) Non-electrostatic binding and selfassociation of amyloid $\beta$-peptide on the surface of tightly packed phosphatidylcholine membranes. Biochem Biophys Res Commun 376:56-59.

Yu L, Edalji R, Harlan JE, Holzman TF, Lopez AP, Labkovsky B, Hillen H, Barghorn S, Ebert U, Richardson PL, Miesbauer L, Solomon L, Bartley D, Walter K, Johnson RW, Hajduk PJ, Olejniczak ET (2009) Structural characterization of a soluble amyloid $\beta$-peptide oligomer. Biochemistry 48:1870-1877. 